(RESEARCH ARTICLE)

\title{
Immunological and molecular detection of rotavirus genotype in calves with gastroenteritis in Diyala-Iraq
}

\author{
Ammar Talib Nasser ${ }^{1}$ Abdulrazak Shafiq Hasan ${ }^{2}$ Amer Khazaal Saleh ${ }^{1}$ and Mohammad Kassem Saleh ${ }^{2 *}$ \\ 1 Diyala University, College of Veterinary Medicine, Baquba, Diyala, Iraq. \\ ${ }^{2}$ Diyala University, College of Medicine, Baquba, Diyala, Iraq.
}

World Journal of Biological and Pharmaceutical Research, 2021, 01(01), 001-013

Publication history: Received on 05 February 2021; revised on 09 March 2021; accepted on 12 March 2021

Article DOI: https://doi.org/10.53346/wjbpr.2021.1.1.0013

\begin{abstract}
Aim: To explore the prevalence of rotavirus infection along with the molecular detection and genotyping of group A rotavirus (RVA) among bovine calves up to 5 months old in Diyala province-Iraq.

Methods: This is a cross sectional study conducted in Diyala province-Iraq during the period of 2019-2020. One hundred bovine calves with age range of 1-5 months were included in the study. All were suffering acute gastroenteritis. Serum anti-rotavirus IgM and IgG plus fecal rotavirus Ag were tested for using ELISA techniques. Stool samples positive for rotavirus Ag were submitted for reverse transcription PCR (RT-PCR) for G and P genes, followed by sequencing and genotyping thereafter. Statistical analysis was done using SPSS version 25 and $\mathrm{P}$ values $\leq 0.05$ were considered significant.
\end{abstract}

Results: The positivity rate of anti-rotavirus IgM was $80 \%(\mathrm{P}=0.0001)$, and that of anti-rotavirus IgG was $79 \%(\mathrm{P}=$ $0.0001)$. The rotavirus stool antigen was detected in $68 \%$ of calves $(P=0.01)$. A total of 45 stool samples which were positive for rotavirus Ag were submitted for RT-PCR; 13 (28.9\%) were positive and $32(71.1 \%)$ were negative $(\mathrm{P}=$ 0.084). 10 PCR positive samples were used for sequencing and genotyping and indicated that all investigated strains belonged to G1P[8] genotype.

Conclusion: The current strains analyzed belonged to the G1P[8] RVA genotypes, affirming that employment of VP7 gene polymorphism accurately yielded uniform phylogenetic distances amongst investigated rotavirus strains and that there were no noticeable assortment events between human and animal rotavirus strains in Diyala province.

Keywords: Rotavirus; Bovine Gastroenteritis; VP7 Genotyping; Diyala Province.

\section{Introduction}

Neonatal calf diarrhea (NCD) is the most common cause of morbidity and mortality, which can exceed 20\% [1]. The factors that influence the etiology of this syndrome include nutritional, sanitary management, immunological aspects, and infectious agents, such as bacteria, viruses, and protozoa [2]. Bovine RVA is one of the most prevalent viral agents associated with NCD in dairy and beef cattle herds worldwide [3]. The non-enveloped virion of RVA is composed of a triple-layered capsid that surrounds 11 dsRNA segments that encode 6 structural (VP1-VP4, VP6, and VP7) and 6 nonstructural (NSP1-NSP6) proteins [4]. Based on their antigenic characteristics and sequence analyses of the VP6 gene, viruses within the rotavirus genus are primarily classified into 9 distinct species (A-I) [5, 6]; the species J was described in the bat [7]. The VP7 and VP4 genes encode 2 structural proteins responsible for the induction of the immune

\footnotetext{
${ }^{*}$ Corresponding author: Mohammad Kassem Saleh

Diyala University, College of Medicine, Baquba, Diyala, Iraq.

Copyright $(2021$ Author(s) retain the copyright of this article. This article is published under the terms of the Creative Commons Attribution Liscense 4.0.
} 
protective response and are used for the binary classification of RVA strains in terms of their G and P genotypes. Currently, $36 \mathrm{G}$ and $51 \mathrm{P}$ genotypes are recognized by the Rotavirus Classification Working Group [8, 9]. Antibodies to rotavirus were found in more than $90 \%$ of unvaccinated cattle, and the virus was isolated from $94 \%$ of dairy calves at a large dairy and calf ranch during the first 2 weeks of life [10]. It was also isolated from approximately $20 \%$ of calf diarrhea samples [11]. Calves become infected after ingesting the virus from fecal contamination of the environment, because the virus remains quite stable if the temperature does not get near freezing. Calves aged 1 to 3 weeks have antibody levels from passive immunity decreasing to a level that is insufficiently high to combat infection [12]. The virus typically affects calves less than 3 weeks old, with a peak incidence at 6 days of age. The incubation period is approximately 24 hours, with resolution of diarrhea in uncomplicated cases in 2 days. Classically, rotavirus diarrhea is thought to be primarily a malabsorptive diarrhea, but toxin-mediated secretory component was affirmed [10].

A molecular study on stool samples of diarrheic calves up to 1 month of dairy farms in two Iranian provinces found that $49.4 \%$ of the samples were positive for bovine RVA, and that G6P[5] was the dominant genotype (35.3\%), followed by G10P[5], G10P[11] and G6P[11], with prevalence rates of $16.5 \%, 15.3 \%$ and $10.6 \%$, respectively, suggesting the importance of producing and implementing an effective bovine rotavirus vaccine [13]. Another study on diarrheic calves from several Turkish geographical areas, reported that overall, G6 was the predominant G type, detected in $75.4 \%$ of samples, while P[11] was the predominant P type, detected in $98.1 \%$ of samples. The most common VP7/VP4 combinations were G6P [11] (60.3\%) and G10P[11] (24.5\%). Mixed infections were identified in 13.2\% of samples [14]. In India, fecal samples of diarrheic calves positive for RVA by ELISA were subjected for RT-PCR to VP7 gene. $60 \%$ of samples were positive, all were characterized as G10 and none of the samples revealed mixed infection by twin G types [15]. Another study on diarrheic buffalo calves and cow calves revealed that $9.73 \%$ were positive for rotavirus. All positive samples showed G10 genotype. This indicates that G10 may be predominant genotype among bovine calves in India [16].

Genotyping analysis of rotavirus positive samples from Australia indicated that G6P[5] was the most prevalent genotype (38.5\%) followed by G6P[5 + 11] (15.4\%). G10P[11] and G6 + G10P[5] were each detected at a rate of 7.7\%, and G6 + $\mathrm{G} 10 \mathrm{P}[11]$ was found, and $30 \%$ of the bovine rotavirus (BRV) positive samples were mixed infections, indicating that individual calves were co-infected with more than one strain of rotavirus [17]. Genotype G6P[11] was found in vaccinated herd and G6P[5] in unvaccinated herd in Brazil. All calves infected with rotavirus presented an episode of diarrhea in the first month of life, and the discrepancy of rotavirus strains circulating in both vaccinated and unvaccinated herds recommend the importance of keeping constant surveillance in order to avoid potential causes of vaccination failure [18].

\section{Material and methods}

This is a cross sectional study conducted in Diyala province-Iraq during the period of 2019-2020. One hundred bovine calves with age range of 1-5 months were included in the study. $46 \%$ were bulls and $54 \%$ were cows. All were suffering acute gastroenteritis, mostly presented with diarrhea. Blood and fecal samples were collected from each calf in veterinary clinics or private farms. Serum anti-rotavirus IgM and IgG plus fecal rotavirus Ag were detected using ELISA techniques (Foresight / China). Stool samples positive for rotavirus Ag were submitted for reverse transcription conventional PCR for G and P genes using highly specific primers (Qiagen, USA), as shown in table 1. PCR detection was followed by sequencing and genotyping thereafter. Statistical analysis was done using SPSS version 25 and P values $\leq$ 0.05 were considered significant.

Table 1 Primers used for VP7 genotyping of human rotavirus strains.

\begin{tabular}{|l|l|l|l|}
\hline $\begin{array}{l}\text { Primer } \\
\text { Name }\end{array}$ & Sequence & $\begin{array}{l}\text { Annealing } \\
\text { temp. }\left({ }^{\circ} \mathbf{C}\right)\end{array}$ & $\begin{array}{l}\text { Product } \\
\text { size (bp) }\end{array}$ \\
\hline Beg 9 & 5'GGCTTTAAAAGAGAGAATTTCCGTCTGG-3` & 42 & 1062 \\
\hline End 9 & 5'-GGTCACATCATACAATTCTAATCTAAG-3 & 42 & 1062 \\
\hline \multicolumn{2}{|c|}{ Primers used for VP7 genotyping of human rotavirus strains [19]. } \\
\hline
\end{tabular}

For sequencing, PCR products were sent for Sanger sequencing using ABI3730XL, automated CDNA sequences, by Macrogen Corporation - Korea. The results were received by e-mail then analyzed using Genious software.

The sequencing results of the PCR products of the targeted samples were edited, aligned, and analyzed with the respective sequences in the reference database using BioEdit Sequence Alignment Editor Software Version 7.1 
(DNASTAR, Madison, WI, USA). The observed variations in each sequenced sample were numbered in PCR amplicons as well as in their corresponding positions within the referring genome. The amino acid sequences of the targeted VP7 protein were retrieved online from the protein data bank (http://www.ncbi.nlm.nih.gov). The observed variants in the coding portions were translated into a reading frame corresponding to the referring amino acid residues using the Expasy online program (http://web.expasy.org/translate/). Multiple amino acid sequences alignments were conducted between the referring amino acid sequences and their observed mutated counterpart using the "align" script of the BioEdit server.

A specific comprehensive tree was constructed according to the neighbor-joining protocol described by Hussein et al. [20]. The observed variants were compared with their neighbor homologous reference sequences using the NCBIBLASTn server [21]. Then, a full inclusive tree, including the observed variant, was built by the neighbor-joining method and visualized as an unrooted tree using iTOL suit. The sequences of each classified phylogenetic species-group in the comprehensive tree were colored appropriately.

This study was approved by the ethical committee in College of Veterinary Medicine - Diyala University.

\section{Results}

A total of 100 bovine calves up to 5 months of age were enrolled, $54 \%$ were cows and $46 \%$ were bulls. $37 \%$ were less than 1 month and $8 \%$ were 5 months old with a mean \pm SD of $12.6 \pm 8.4$ weeks and a range of 3-21 weeks. Clinical signs included fever, vomiting and diarrhea. The results of ELISA techniques found that the anti-rotavirus IgM positivity rate was $80 \%$ with a statistically significant difference $(\mathrm{P}=0.0001)$. Furthermore, $79 \%$ were anti-rotavirus IgG positive with a statistically significant difference $(\mathrm{P}=0.0001)$. The rotavirus stool antigen was positive in $68 \%$ of samples with statistically significant difference $(\mathrm{P}=0.01)$, as shown in table 2.

Table 2 Serum anti-rotavirus IgM, IgG and fecal rotavirus Ag of study group.

\begin{tabular}{|l|l|l|l|l|}
\hline \multicolumn{2}{|l|}{ Immunological results } & No. & \% & P value \\
\hline \multirow{3}{*}{ Anti-rotavirus IgM } & Positive & 80 & 80.0 & \multirow{2}{*}{$0.0001^{*}$} \\
\cline { 2 - 5 } & Negative & 20 & 20.0 & \multirow{2}{*}{$0.0001^{*}$} \\
\hline \multirow{3}{*}{ Anti-rotavirus IgG } & Positive & 79 & 79.0 & \multirow{2}{*}{$0.01^{*}$} \\
\cline { 2 - 5 } & Negative & 21 & 21.0 & 68.0 \\
\hline \multirow{2}{*}{ Stool rotavirus Ag } & Positive & 68 & 32.0 & \\
\cline { 2 - 5 } & Negative & 32 & & \\
\hline
\end{tabular}

*Significant difference between proportions by Pearson Chi-square test at 0.05 level.

A total of 45 stool samples were submitted for PCR detection; 13 (28.9\%) were positive and 32 (71.1\%) were negative with insignificant difference $(\mathrm{P}=0.084)$, as shown in table 3 .

Table 3 Fecal rotavirus RNA detection rate by PCR technique.

\begin{tabular}{|l|l|l|l|}
\hline PCR detection & No. & $\mathbf{\%}$ & P value \\
\hline Positive & 13 & 28.9 & \multirow{2}{*}{$0.084^{*}$} \\
\hline Negative & 32 & 71.1 & \\
\hline
\end{tabular}

Data also revealed that anti-rotavirus IgG positivity was insignificantly associated with the PCR outcome $(\mathrm{P}=0.375)$. On the other hand, the anti-rotavirus IgM positivity was significantly associated with the positive PCR outcome $(\mathrm{P}=$ 0.033 ), as shown in table 4 . 
Table 4 Association of anti-rotavirus IgG and IgM with PCR outcome.

\begin{tabular}{|l|l|l|l|l|l|l|l|l|}
\hline \multirow{2}{*}{$\begin{array}{l}\text { PCR } \\
\text { outcome }\end{array}$} & \multicolumn{4}{l}{ Anti-rotavirus IgG } & \multicolumn{3}{l|}{ Anti-rotavirus IgM } \\
\cline { 2 - 10 } & Positive & Negative & \multicolumn{2}{l|}{ Positive } & Negative \\
\cline { 2 - 10 } & No. & $\%$ & No. & $\%$ & No. & $\%$ & No. & $\%$ \\
\hline Positive & 10 & 76.9 & 3 & 23.1 & 13 & 100.0 & - & - \\
\hline Negative & 28 & 87.5 & 4 & 12.5 & 23 & 71.9 & 9 & 28.1 \\
\hline P value & 0.375 & *Significant difference between proportions using Pearson Chi-square test at 0.05 level. & $0.033^{*}$ & \\
\hline
\end{tabular}

The rotavirus stool antigen positivity rate was significantly associated with male calves $(\mathrm{P}=0.004)$. Furthermore, the PCR positive outcome was significantly higher in female calves $(P=0.020)$, as revealed in table 5.

Table 5 Association of stool Ag and PCR outcome with gender.

\begin{tabular}{|c|c|c|c|c|c|c|c|c|}
\hline \multirow{3}{*}{ Gender } & \multicolumn{4}{|c|}{ Rotavirus stool Ag } & \multicolumn{4}{|c|}{ PCR outcome } \\
\hline & \multicolumn{2}{|c|}{ Positive } & \multicolumn{2}{|c|}{ Negative } & \multicolumn{2}{|c|}{ Positive } & \multicolumn{2}{|c|}{ Negative } \\
\hline & No. & $\%$ & No. & $\%$ & No. & $\%$ & No. & $\%$ \\
\hline Male & 38 & 82.6 & 8 & 17.4 & 2 & 10.5 & 17 & 89.5 \\
\hline Female & 30 & 55.6 & 24 & 44.4 & 11 & 42.3 & 15 & 57.7 \\
\hline$P$ value & \multicolumn{4}{|c|}{$0.004^{*}$} & \multicolumn{4}{|c|}{$0.020 *$} \\
\hline
\end{tabular}

Data presented in table 6 found that the stool rotavirus antigen positivity was insignificantly associated with antirotavirus IgM positivity $(\mathrm{P}=0.230)$. Whereas, the PCR positive outcome was significantly associated with the antirotavirus IgM positivity $(\mathrm{P}=0.033)$.

Table 6 Association of stool Ag and PCR outcome with IgM positivity.

\begin{tabular}{|l|l|l|l|l|l|l|l|l|}
\hline \multirow{2}{*}{ IgM positivity } & \multicolumn{2}{l}{ Rotavirus stool Ag } & \multicolumn{3}{l|}{ PCR outcome } \\
\cline { 2 - 10 } & Positive & Negative & \multicolumn{2}{l|}{ Positive } & Negative \\
\cline { 2 - 10 } & No. & $\%$ & No. & $\%$ & No. & $\%$ & No. & $\%$ \\
\hline Positive & 56 & 70.9 & 23 & 29.1 & 13 & 36.1 & 23 & 63.9 \\
\hline Negative & 12 & 57.1 & 9 & 42.9 & - & - & 9 & 100 \\
\hline P value & 0.230 & *Significant difference between proportions using Pearson Chi-square test at 0.05 level. \\
\hline
\end{tabular}

The results also revealed that the rotavirus stool antigen positivity was insignificantly associated with the anti-rotavirus IgG negativity $(\mathrm{P}=0.830)$. Moreover, the PCR positive outcome was insignificantly associated with the anti-rotavirus IgG negativity $(\mathrm{P}=0.375)$, as shown in table 7 . 
Table 7 Association of stool Ag and PCR outcome with IgG positivity.

\begin{tabular}{|l|l|l|l|l|l|l|l|l|}
\hline \multirow{3}{*}{$\begin{array}{l}\text { IgG } \\
\text { positivity }\end{array}$} & \multicolumn{9}{|l}{ Rotavirus stool Ag } & \multicolumn{3}{l|}{ PCR outcome } \\
\cline { 2 - 10 } & Positive & Negative & Positive & Negative \\
\cline { 2 - 10 } & No. & $\%$ & No. & $\%$ & No. & $\%$ & No. & $\%$ \\
\hline Positive & 54 & 67.5 & 26 & 32.5 & 10 & 26.3 & 28 & 73.7 \\
\hline Negative & 14 & 70.0 & 6 & 30.0 & 3 & 42.9 & 4 & 57.1 \\
\hline P value & $0.830^{*}$ & *Insignificant difference between proportions using Pearson Chi-square test at 0.05 level. \\
\hline
\end{tabular}

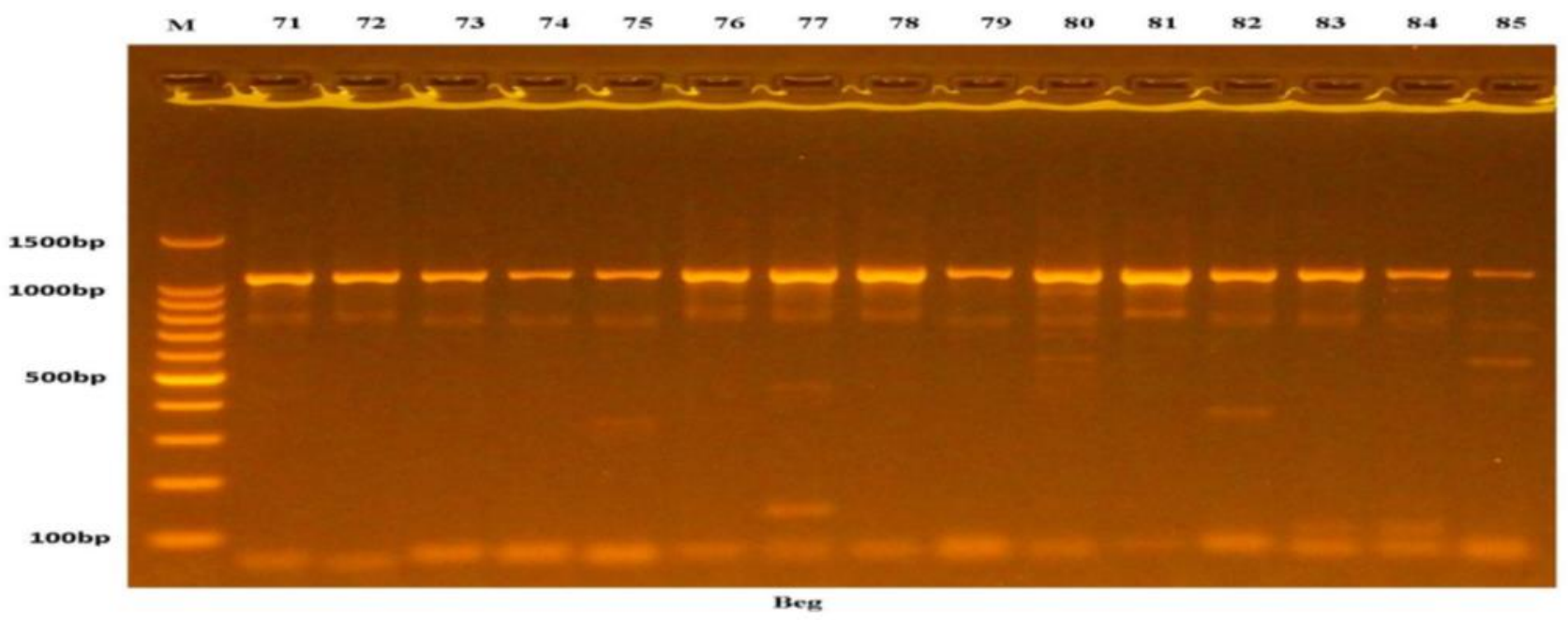

Figure 1 Results of the amplification of rotavirus gene of stool samples were fractionated on $2 \%$ agarose gel electrophoresis stained with Eth.Br. M: 100bp ladder marker. Lanes 71-85 resemble 1062bp PCR products.

For the sequencing, 10 PCR positive products were included. These were screened to amplify VP7 gene sequences of rotavirus. The outer capsid protein is one of the structural proteins encoded by rotaviral VP7 gene. Thus, the variation of VP7 gene can be used for rotavirus genotyping due to its ability to adapt remarkable genetic diversity among different viral sequences [22]. The sequencing reactions indicated the exact identity after performing NCBI BLASTn for these PCR amplicons [21]. Concerning the 1062 bp amplicons, the NCBI BLASTn engine has shown about 98\% sequences similarities between the sequenced samples and the intended reference target sequences. By comparing the observed nucleic acid sequences of these investigated samples with the retrieved nucleic acid sequences (GenBank acc. GQ452920.3), the accurate positions and other details of the retrieved PCR fragments were identified. The total length of the targeted locus was localized in the NCBI server, and the positions of the start and end of the targeted locus were also confirmed (as shown in figure 2).

After positioning the $1062 \mathrm{bp}$ amplicons' sequences within the genomic sequences of rotavirus, the details of its sequences were highlighted, in terms of the positioning of both forward and reverse primers of the $1062 \mathrm{bp}$ amplified amplicons, as shown in table 8. 


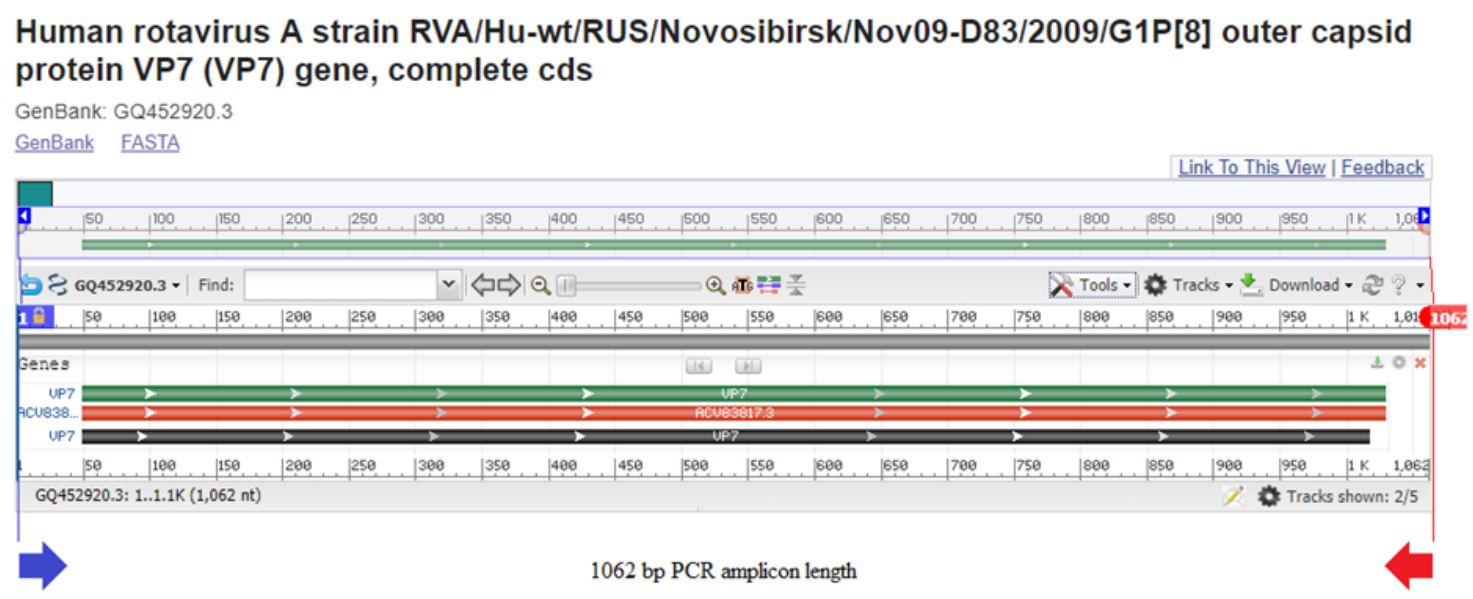

Figure 2 The exact position of the retrieved $1062 \mathrm{bp}$ amplicon that partially covered a portion of the VP7 gene within rotavirus genomic sequences (GenBank acc no. GQ452920.3). The cyan arrow refers to the starting point of this amplicon while the red arrow refers to its endpoint.

Table 8 The position and length of the 1062 bp PCR amplicons that were used to amplify a portion of the VP7 gene within rotavirus genomic sequences (GenBank acc. no. GQ452920.3). The gray-colored sequences refer to the position of the reverse and forward primers, respectively.

\begin{tabular}{|c|c|c|}
\hline Amplicon & Reference locus sequences $\left(5^{\prime}-3^{\prime}\right)$ & length \\
\hline $\begin{array}{l}\text { Nucleic acid sequences } \\
\text { within the viral VP7 } \\
\text { genetic locus }\end{array}$ & $\begin{array}{l}\text { *GGCTTTAAAAGAGAGAATTTCCGTCTGGCTAACGGTTAGCTC } \\
\text { CTTTTGATGTATGGTATTGAATATACCACAATTCTAATCTTTC } \\
\text { TGATATCAATCATTCTATTCAACTATATATTAAAATCAGTGAC } \\
\text { TCAAATGATGGACTACCTTATATATAGATCTTTGTTAATTCT } \\
\text { GTAGCATTATTTGCCTTGACAAGAGCTCAGAATTATGGGATTA } \\
\text { ACTTACCAATAACAGGATCAATGGACGCCGCATACGCTAACTC } \\
\text { TACTCAAGAAGGAATATTTCTAACATCCACATTATGTCTGTAT } \\
\text { TATCCGACAGAAGCAAGTACTCAAATTAATGATGGTGAATGGA } \\
\text { AAGACTCATTATCACAAATGTTTCTCACAAAAGGTTGGCCAAC } \\
\text { AGGATCAGTCTATTTTAAAGAGTATTCAAGTATTGTTGATTTT } \\
\text { TCTGTTGATCCACAATTATATTGTGATTATAACTTAGTACTAA } \\
\text { TGAAATATGATCAAAATCTTGAATTAGATATGTCAGAGTTAGC } \\
\text { TGATTTAATATTGAATGAATGGTTATGTAATCCAATGGATATA } \\
\text { ACATTATATTATTATCAACAATCAGGAGAATCAAACAAGTGGA } \\
\text { TATCAATGGGATCATCATGTACTGTGAAAGTGTGTCCACTGAA } \\
\text { TACGCAAACGTTAGGAATAGGCTGTCAAACAACAAATGTAGAC } \\
\text { TCGTTTGAAATGGTTGCTGAAAATGAGAAATTAGCTATAGTGG } \\
\text { ATGTCGTTGATGGGATAAATCATAAAATAAATTTGACAACTAC } \\
\text { GACATGTACTATTCGAAATTGTAAGAAGTTAGGTCCAAGAGAG } \\
\text { AATGTAGCTGTAATACAGGTTGGTGGCTCTAATGTATTAGACA } \\
\text { TAACAGCAGATCCAACGACTAATCCACAAACTGAGAGAATGAT } \\
\text { GAGAGTGAATTGGAAAAAATGGTGGCAAGTATTTTATACTAT } \\
\text { AGTAGATTATATTAACCAGATTGTACAGGTAATGTCCAAAAGA } \\
\text { TCAAGATCATTAAATTCTGCAGCTTTTTATTATAGAGTATAGA } \\
\text { TATACCTTAGATTAGAATTGTATGATGTGACC** }\end{array}$ & $1062 \mathrm{bp}$ \\
\hline
\end{tabular}

To summarize all the results obtained from the sequenced $1062 \mathrm{bp}$ fragments, the precise positions and annotations of the observed nucleic acid substitution mutation is described in the NCBI reference sequences as shown in table 9. 
Table 9 The pattern of the observed SNPs in the $1062 \mathrm{bp}$ amplicons of the VP7 gene in comparison with the NCBI referring sequences (GenBank acc. no. GQ452920.3). The symbol "S" followed by a number refers to the numbers of the investigated viral sample.

\begin{tabular}{|c|c|c|c|c|c|c|c|}
\hline $\begin{array}{l}\text { Sample } \\
\text { No. }\end{array}$ & Native & Allele & $\begin{array}{l}\text { Position in } \\
\text { the PCR } \\
\text { fragment }\end{array}$ & $\begin{array}{l}\text { Position in } \\
\text { the } \\
\text { reference } \\
\text { genome }\end{array}$ & $\begin{array}{l}\text { Amino } \\
\text { acid } \\
\text { position }\end{array}$ & Type of mutation & $\begin{array}{l}\text { Mutation } \\
\text { summary }\end{array}$ \\
\hline All & A & G & 177 & 177 & Ala43 & Silent (p.Ala43=) & g.177 $A>G$ \\
\hline All & A & G & 180 & 180 & Leu44 & Silent (p.Leu44=) & g.180 A>G \\
\hline S1-S9 & A & G & 192 & 192 & Thr48 & Silent (p.Thr48=) & g.192 A>G \\
\hline All & $\mathrm{T}$ & $\mathrm{C}$ & 300 & 300 & Tyr84 & Silent (p.Tyr84=) & g. $300 \mathrm{~T}>\mathrm{C}$ \\
\hline S7 & $\mathrm{T}$ & A & 427 & 427 & Phe127 & Missense (p.Phe127Ile) & g.427 T>A \\
\hline All & $\mathrm{C}$ & $\mathrm{T}$ & 594 & 594 & Asn182 & Silent (p.Asn182=) & g.594 C>T \\
\hline All & $\mathrm{C}$ & $\mathrm{T}$ & 666 & 666 & Gly206 & Silent (p.Gly206=) & g. $666 \mathrm{C}>\mathrm{T}$ \\
\hline All & $\mathrm{C}$ & $\mathrm{T}$ & 751 & 751 & His235 & Missense (p.His235Tyr) & g.751 C>T \\
\hline All & $\mathrm{T}$ & $\mathrm{C}$ & 846 & 846 & Ser266 & Silent (p.Ser266=) & g.846 $\mathrm{T}>\mathrm{C}$ \\
\hline All & $\mathrm{C}$ & $\mathrm{T}$ & 890 & 890 & Thr281 & Missense (p.Thr281Ile) & g.890 C>T \\
\hline All & G & A & 1009 & 1009 & Ala321 & Missense (p.Ala321Thr) & g.1009 G>A \\
\hline
\end{tabular}

A comprehensive phylogenetic tree was generated according to the amplified $1062 \mathrm{bp}$ of the VP7 amplicons. This phylogenetic tree contained S1 to S10 samples alongside other relative nucleic acid sequences of rotavirus sequences. The total number of the aligned nucleic acid sequences in this comprehensive tree was 111 . The rotavirus sequences are the only incorporated organism within the tree. Noteworthy, the investigated samples were clustered into several adjacent clades within the rotavirus sequences, as shown in figure 3.

The genetic variations of the coding regions of the VP7 gene of rotavirus were further investigated using a neighbor joining - based phylogenetic analyses based on the versatile role of the protein encoded by the VP7 gene [23].

The VP7 gene polymorphism is one of the main key factors in the determination of the rotavirus genotype. One genetic fragment covering the entire coding region of the VP7 gene was amplified in this study. Subsequently, a direct sequencing strategy was performed for the observed PCR amplicons to assess the pattern of genetic polymorphism in the screened specimens. Then, a specific comprehensive tree was built to assess the phylogenetic positions of the observed variants. The current results indicated the presence of eleven nucleic acid variations distributed in almost all the investigated samples. All investigated viral samples belonged to G1P[8] genotype. In conclusion, the utilization of VP7 gene polymorphism has precisely given uniform phylogenetic distances amongst all investigated rotavirus samples. These data may suggest no noticeable assortment events between human and animal rotavirus strains in the investigated area. 


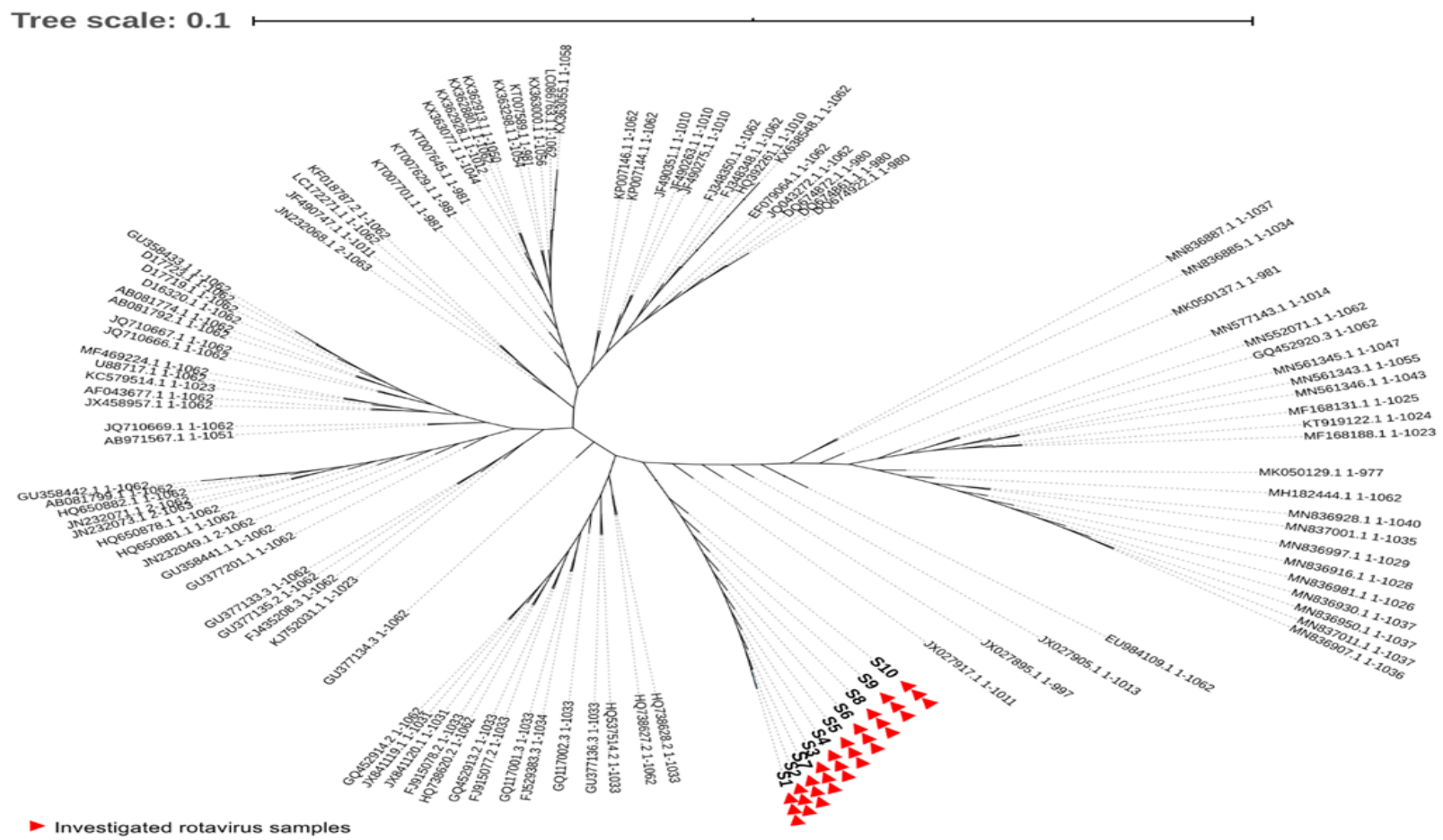

Figure 3 The comprehensive unrooted phylogenetic tree of genetic variants of the VP7 fragment of ten rotavirus local samples. The red triangles refer to the analyzed viral variants. All the mentioned numbers referred to GenBank accession number of each referring species. The number " 0.1 " at the top portion of the tree refers to the degree of scale range among the comprehensive tree categorized organisms. The letter "S\#" refers to the code of the investigated samples.

\section{Discussion}

The current results showed that there was significantly high rate of rotavirus infection as represented by detected IgM, and seroprevalence as represented by detected IgG as well as the rotavirus stool Ag. These results are consistent with the $82 \%$ infection rate obtained in a local study [24]. Other local studies also documented the infection of calves and buffalo in Iraq $[25,26]$. These results also agree with other studies confirming the high rate of infection among calves in Iran [13], as well as in Argentina, where the infection rate was (81\%) [27]. However, this study is inconsistent with other studies that reported lower infection rates; for instance, $30 \%$ of Tunisian calves had positive stool rotavirus Ag as detected by EIA [28]. 53\% in Oman [29]. In India, A fecal rotavirus antigen was detected in 9.59\% of cow calves by ELISA technique [30]. Other studies conducted in North India by employing ELISA, reported prevalence rates of 4.61\%, $15.41 \%$ and $15.68 \%$, among diarrheic bovine calves [31-33]. Additionally, 37\% of NCD in dairy and beef herds in northern Italy were found to be positive for group A bovine rotavirus by a specific ELISA [34]. The difference in the detection rate of stool rotavirus Ag among calves between previous studies on one hand, and the current study on the other, may be attributed to the existence of different rotavirus genotypes, employment of animal vaccines and sensitivity of laboratory techniques used.

In this study, utilization of the ELISA technique for calf serology revealed a high rate of IgG (79\%). These results are in agreement with local studies [35]. They are also similar to results of a study conducted in Turkey [36]. However, the current results are less than the results obtained in some international studies, including one conducted in the USA which found a prevalence of $87 \%$ and $13 \%$ in calves with diarrhea and without diarrhea, respectively [37]. The intra and inter country differences in the prevalence of rotavirus infection may have been influenced by different factors that may have fluctuated among regions including spatial, temporal, management and host related factors as well as by the factors that may vary between studies including study design, sample size, analytical strategy and crucially by the sensitivity of the diagnostic tests used.

Regarding the calf infection, primarily $86 \%$ of fecal samples were positive for rotaviral Ag, while the rotavirus RNA was detected in $28.9 \%$ by conventional PCR. Upon reviewing the literature, in Tunisia, using ELISA, the stool rotavirus Ag 
was positive in $23.3 \%$ of specimens, and by polyacrylamide gel electrophoresis (PAGE), $94.4 \%$ of these specimens were positive for RVA [28]. Similarly, higher rate of rotavirus RNA detection by PCR was obtained in Italy, as $37.1 \%$ of fecal samples collected from outbreak of NCD in dairy and beef herds were positive for group A bovine rotavirus by ELISA and all (100\%) of these were positive for the G and P serotypes by a nested RT-PCR typing assay [34]. In Iran, a study that screened the presence of bovine RVA by RT-PCR in stool samples of diarrheic calves up to 1 month old from two Iranian provinces, found that the detection rate was $35.3 \%$ affirming the diversity of G and P genotypes in bovine RVA samples from diarrheic calves [13]. In another study on fecal samples collected from calves with diarrhea using a seminested RT-PCR, the rate of detection ranged from $50.6 \%$ to $64 \%$, suggesting that identification of G/P genotypes and their diversity is fundamental to development and use of effective vaccines [38]. In another neighboring country, Turkey, a study that conducted RT-PCR genotyping of rotavirus from diarrheic calves from several Turkish geographical areas, found that the detection rate ranged from $75.4 \%$ to $98.1 \%$ depending on the genotype combination [14].

In India, diarrheic stool samples of buffalo calves and cow calves were screened by RNA-PAGE for the presence of rotavirus, and then subjected to RT-PCR for VP7 gene, and genotyping [16]. In another study, fecal samples of diarrheic calves positive for RVA by ELISA, were subjected to RT-PCR and the amplified products were subjected to G-typing [15]. Both studies reported variable rates of detection depending on the genotypes detected. It is clear that the molecular studies had reported different detection rates depending on geographical region, rotavirus genotypes prevalent and laboratory techniques used.

The higher rate of IgG among those calves less than one month of age may be related to the maternal IgG that is passively transferred from mother prenatally through the placenta and postnatally through sucking milk while the IgM peak was delayed to first few months of life [39,40]. Similar results were also reported in local studies [24,41], as well as abroad. It is well documented that rotavirus was one of the first identified viral causes of diarrhea, and was initially known as NCD virus. Subsequently, it was found throughout the world and was identified as a significant pathogen of children and most other mammals [3]. Antibodies to rotavirus were found in more than $90 \%$ of unvaccinated cattle, and the virus was isolated from $94 \%$ of dairy calves at a large dairy and calf ranch during the first 2 weeks of life [1]. The virus typically affects calves less than 3 weeks old, with a peak incidence at 6 days of age. Classically, rotavirus diarrhea is thought to be primarily a malabsorptive diarrhea, but evidence indicates that there is also a toxin-mediated secretory component as well [10].

The current molecular results also revealed that the predominant rotavirus genotype among calves was the G1P[8]. Unfortunately, there were no previous studies on rotavirus genotyping among calves in Iraq. However, concerning the neighbor countries, the current results were inconsistent with those reported by Pourasgari et al., who screened the presence of bovine RVA by RT-PCR in stool samples of diarrheic calves up to 1 month old. The G6P[5] was the dominant genotype (35.3 \%), followed by G10P[5], G10P[11] and G6P[11], affirming the diversity of G and P genotypes in bovine RVA samples from diarrheic Iranian calves [13]. In another study on fecal samples collected from calves with diarrhea using a semi-nested RT-PCR in Iran, G10 (50.6\%) and P[11] (64\%) were detected more than G6 (21.3\%) and P[5] (9.3\%). No G8 and P[1] were observed, and the most common VP7/VP4 combinations were G10P[11] (40\%), G6P[11] (12\%), G6P[5] (5.3\%) and G10P[5] (2.6\%), suggesting that identification of G/P genotypes and their diversity is fundamental to development and use of effective vaccines [38]. On the Turkish side, the current results were also inconsistent with a study that conducted RT-PCR genotyping of rotavirus from diarrheic calves from several Turkish geographical areas. The overall, G6 was the predominant G type, detected in 40/53 samples (75.4\%), while P[11] was the predominant $\mathrm{P}$ type, detected in 52/53 samples (98.1\%). The most common VP7/VP4 combinations were G6P[11] (60.3\%) and G10P[11] (24.5\%). Mixed infections were identified in 7/53 samples (13.2\%) [14].

On the global side, the current results also disagreed with those of a study conducted in Tunisia for molecular typing of rotavirus from dairy calves and G8 genotype was found to be the most prevalent, but G6 and mixed strains G(6+8) were also detected [28]. Similarly, current results were inconsistent with those of a study that reported various combinations of $\mathrm{G}$ and $\mathrm{P}$ serotypes of rotavirus among calves with clinical signs of neonatal diarrhea in Italy, since the most frequently detected genotypes were G6P[5] (38.3\%), G10,P[11] (31.5\%), and G6,P[11] (15.4\%) [34]. In India, diarrheic samples of buffalo calves and cow calves were screened by RNA-PAGE for the presence of rotavirus, and then subjected to RT-PCR for VP7 gene, and genotyping for G6, G8 and G10 genotype. All positive samples showed G10 genotype, indicating that G10 may be the predominant genotype among calves in India [16]. In another study, fecal samples of diarrheic calves positive for RVA by ELISA, were subjected to RT-PCR and the amplified products were subjected to G-typing and found that all were G10 and none of the samples revealed mixed infection [15]. The present results were also inconsistent with those reported from Australia that found that Group A BRV was detected in $26 \%$ of fecal samples from calves with diarrhea and asymptomatic calves and the G6P[5] was the most prevalent genotype (38.5\%) followed by G6P[5 + 11] (15.4\%). G10P[11] and G6 + G10P[5] were each detected at a rate of 7.7\%, and G6 + 
G10P[11] was found in a single sample (3.8\%) plus 30\% of the BRV positive samples were mixed infections, indicating that individual calves were co-infected with more than one strain of rotavirus [17].

Another important result of sequence genotyping of the current G1P[8] rotavirus is the absence of reassortment. This result may be related to non-employment of bovine rotavirus vaccine for calves and recent introduction of human rotavirus vaccines (since 2014) in Iraq. Several molecular studies had reported genotypic changes of rotavirus as a result of vaccine pressure [42-44]. These rotavirus vaccines were designed to protect against disease caused by the most prevalent strain types; globally, G1P[8], G2P [4], G3P [8], G4P[8], G9P[8] and G12 in combination with P[6] or P[8] account for over $90 \%$ of the genotypes that infect humans [45]. Accordingly and based on the current rotavirus genotype G1P[8] detected in Diyala province, the current study is speculating that the rotavirus vaccine under use in Iraq (RV5; RotaTeq, Merck) is still protective for human vaccinees, as the currently used vaccine was designed to provide protection against the most common rotavirus serotypes (G1, G2, G3, G4, G9) and be able to decrease disease severity, reduce hospitalizations, and decrease disease-related costs [46].

The current study suggests that a special focus should be directed towards the rotavirus genotypic changes that occurred in Turkey, Iran and Syria (unfortunately no data available online), since the Tigris and Euphrates arise and/or flow across their mainland and as it is well known that Iraqi people are largely dependent on these two rivers for irrigation and municipal supply. Of note, it was widely documented that human or animal sewage contaminated water is the main vehicle for rotavirus transmission [47, 48]. Additionally, during the last few years, active trading of different fresh or processed foods from these countries became much more common [49]. The current study suggests that collectively these sources may impact the rotavirus epidemiology in Iraq.

In this study, another fascinating result was that the common rotavirus genotype G1P[8] was detected from both children as well as calves. Similar results were obtained from a Nigerian study which reported a human rotavirus in diarrheic calves aged 29-56 days, that was explained by the close association between the herdsmen and their animals and the sharing of a common source of drinking water in the predominantly livestock-producing communities [50]. Furthermore, a previous study reported that interspecies transmission between livestock, domestic animals and humans is commonly observed [51]. In Diyala community, the first impression of this result points to the common source of transmission of rotavirus infection in both human and calves. In this regard the most incriminated route is contaminated water. It is well documented that the drinking water is the primary source of rotavirus infection and outbreaks among humans and animals particularly in low-income communities $[47,48]$. It is important to remember that viral shedding with the stool in clinical or asymptomatic rotavirus infection continues for up to 57 days post exposure [52]. What is aggravating the situation in communities like that in Diyala is that the human and animal excreta return to the rivers successively as sewage treatment stations are absent and that the municipal water repumping stations are located on the same rivers. So, the epidemiological trajectory cycle of rotavirus passes through three stages; human or animals, excreta, water, and human or animals again [53,54]. Additionally, Diyala province is an agricultural one and people are used to breeding domesticated animals in or near their houses. Therefore, the direct contact with these animals may hasten virus interspecies transmission [55, 56]. Furthermore, human and animal excreta are still being used as a fertilizer for vegetables and of course the most dangerous of these are those eaten fresh without cooking as a source of rotavirus infection $[49,57]$. Eventually, even pet animals were proved to be able to transmit rotavirus to human [51]. In connection with interspecies transmission of rotavirus, it has been reported that there were genetic reassortants containing segments from a number of animal species and/or humans (interspecies transmission by reassorted animal rotaviruses) and viruses in which all segments were from the same animal species (interspecies transmission by non-reassorted animal rotaviruses). Molecular analysis has documented many more examples of interspecies transmission of genetic reassortants. Among the earliest documented reassortants were two G3P [3] human strains that were shown to be rotaviruses of canine/feline origin [58]. Accordingly, the present study pointed out the importance of continuous surveillance studies to follow up any changes in local rotavirus genotype.

\section{Conclusion}

All the investigated strains in this study belong to G1P[8] genotype, with no noticeable assortment events between human and animal rotavirus strains in Diyala province. Since the Tigris and Euphrates arise and/or flow across the mainland of Turkey, Iran and Syria, and Iraqi people are largely dependent on these two rivers for irrigation and municipal supply, special focus should be directed towards the rotavirus genotypic changes in these countries. Moreover, continuous follow-up of changes in rotavirus genotypes through molecular surveillance and vigilant system for persistent clarification of epidemiological changes and for monitoring rotavirus vaccine employment, should be exercised in Iraq. 


\section{Compliance with ethical standards}

\section{Acknowledgments}

We would like to thank each and every individual who have been a source of support and encouragement and helped us achieve our goal and complete this study successfully.

\section{Disclosure of conflict of interest}

All authors declare that they have no conflict of interest.

\section{Statement of ethical approval}

This study was approved by the ethical committee in College of Veterinary Medicine - Diyala University.

\section{References}

[1] Uetake K. Newborn calf welfare: a review focusing on mortality rates. Anim Sci J. 2013; 84(2):101-105.

[2] Coura FM, Freitas MD, Ribeiro J, et al. Longitudinal study of Salmonella spp., diarrheagenic Escherichia coli, Rotavirus, and Coronavirus isolated from healthy and diarrheic calves in a Brazilian dairy herd. Trop Anim Health Prod. 2015; 47(1):3-11.

[3] Al Mawly J, Grinberg A, Prattley D, Moffat J, Marshall J, French N. Risk factors for neonatal calf diarrhoea and enteropathogen shedding in New Zealand dairy farms. Vet J. 2015; 203(2):155-160.

[4] Bass DM, Kliegman RM, Stanton BF, Geme JW, Schor NF, Behrman RE. Nelson Text Book of Pediatrics. $20^{\text {th }}$ ed. Philadelphia: Elsevier Saunders; 2017; P.1616-1618.

[5] Matthijnssens J, Otto PH, Ciarlet M, Desselberger U, Van Ranst M, Johne R. VP6-sequence-based cutoff values as a criterion for rotavirus species demarcation. Arch Virol. 2012; 157(6):1177-1182.

[6] Mihalov-Kovács E, Gellért Á, Marton S, et al. Candidate new rotavirus species in sheltered dogs, Hungary. Emerg Infect Dis. 2015; 21(4):660-663.

[7] Bányai K, Kemenesi G, Budinski I, et al. Candidate new rotavirus species in Schreiber's bats, Serbia. Infect Genet Evol. 2017; 48:19-26.

[8] Rotavirus Classification Working Group: RCWG. Newly Assigned Genotypes - June $30^{\text {th }} 2017$ [internet]. Flanders: Katholieke Universiteit Leuven; 2017 [cited 2020 Nov 12]. Available from: https://rega.kuleuven.be/cev/viralmetagenomics/virus-classification/rcwg

[9] Buttafuoco A, Michaelsen K, Tobler K, Ackermann M, Fraefel C, Eichwald C. Conserved Rotavirus NSP5 and VP2 Domains Interact and Affect Viroplasm. J Virol. 2020; 94(7):e01965-19.

[10] Foster DM, Smith GW. Pathophysiology of diarrhea in calves. Vet Clin North Am Food Anim Pract. 2009; 25(1):1336.

[11] Alfieri AA, Parazzi ME, Takiuchi E, Médici KC, Alfieri AF. Frequency of group A rotavirus in diarrhoeic calves in Brazilian cattle herds, 1998-2002. Trop Anim Health Prod. 2006; 38(7-8):521-526.

[12] Chase CC, Hurley DJ, Reber AJ. Neonatal immune development in the calf and its impact on vaccine response. Vet Clin North Am Food Anim Pract. 2008; 24(1):87-104.

[13] Pourasgari F, Kaplon J, Karimi-Naghlani S, et al. The molecular epidemiology of bovine rotaviruses circulating in Iran: a two-year study. Arch Virol. 2016; 161(12):3483-3494.

[14] Alkan F, Ozkul A, Oguzoglu TC, et al. Distribution of G (VP7) and P (VP4) genotypes of group A bovine rotaviruses from Turkish calves with diarrhea, 1997-2008. Vet Microbiol. 2010; 141(3-4):231-237.

[15] Wani SA, Bhat MA, Ishaq SM, Ashrafi MA. Determination of bovine rotavirus G genotypes in Kashmir, India. Rev Sci Tech. 2004; 23(3):931-936.

[16] Mondal A, Aich R, Majee S, Bannalikar AS. Determination of bovine rotavirus G serotype by polymerase chain reaction. Trop Anim Health Prod. 2012; 44(4):763-767. 
[17] Swiatek DL, Palombo EA, Lee A, Coventry MJ, Britz ML, Kirkwood CD. Detection and analysis of bovine rotavirus strains circulating in Australian calves during 2004 and 2005. Vet Microbiol. 2010; 140(1-2):56-62.

[18] Rocha TG, Silva FD, Gregori F, Alfieri AA, Buzinaro MD, Fagliari JJ. Longitudinal study of bovine rotavirus group A in newborn calves from vaccinated and unvaccinated dairy herds. Trop Anim Health Prod. 2017; 49(4):783-790.

[19] Chouikha A, Fredj MB, Fodha I, et al. Évolution des souches de Rotavirus du groupe A en circulation en Tunisie sur une période de trois ans (2005-2007) [Evolution of group A Rotavirus strains circulating in Tunisia over a 3year period (2005-2007)]. Pathol Biol (Paris). 2011; 59(4):e79-e83.

[20] Hussein TH, Al-Shuhaib MBS, Al-Thuwaini TM. Potential mitochondrial diversity role in the productivity of three lines of Japanese quails. Biodiversitas. 2020; 21(5):2258-2265.

[21] Zhang Z, Schwartz S, Wagner L, Miller W. A greedy algorithm for aligning DNA sequences. J Comput Biol. 2000; 7(1-2):203-214.

[22] Sadiq A, Bostan N, Bokhari H, et al. Molecular characterization of human group A rotavirus genotypes circulating in Rawalpindi, Islamabad, Pakistan during 2015-2016. PLoS One. 2019; 14(7):e0220387.

[23] Intamaso U, Poomipak W, Chutoam P, Chotchuang P, Sunkkham W, et al. Genotype Distribution and Phylogenetic Analysis of Rotaviruses in Thailand and Emergence of Uncommon Genotypes. Arch Clin Microbiol. 2017; 8(4):6070 .

[24] Hekmat KA. Detection of rotavirus antigens and antibodies in children and bovine calves [M.Sc. thesis]. Basrah, Iraq: University of Basrah - College of Veterinary Medicine; 2016.

[25] Hasso SA Pandey R. Detection of rotavirus antigen from buffalo calves in Iraq. J Diarrheal Dis Res. 1990; 8(4):168169.

[26] Ateya HK. Detection of rotavirus antigens and antibodies in children and bovine [M.Sc. thesis]. Basrah, Iraq: University of Basrah - College of Veterinary Medicine; 2010.

[27] Badaracco A, Garaicoechea L, Rodríguez D, et al. Bovine rotavirus strains circulating in beef and dairy herds in Argentina from 2004 to 2010. Vet Microbiol. 2012; 158(3-4):394-399.

[28] Fodha I, Boumaiza A, Chouikha A, et al. Detection of group a rotavirus strains circulating in calves in Tunisia. J Vet Med B Infect Dis Vet Public Health. 2005; 52(1):49-50.

[29] Aithala G, Al Dhahry SH, Saha A, Elbualy MS. Epidemiological and clinical features of rotavirus gastroenteritis in Oman. J Trop Pediatr. 1996; 42(1):54-57.

[30] Gill GS, Kaur S, Dwivedi PN, Gill, JP. Prevalence and Molecular Characterization of Group a Rotavirus in Children of Punjab, India. Int J Curr Microbiol App Sci. 2017; 6(22):1231-1242.

[31] Manuja BK, Prasad M, Manuja A, Gulati BR, Prasad G. A novel genomic constellation (G10P[3]) of group A rotavirus detected from buffalo calves in northern India. Virus Res. 2008; 138(1-2):36-42.

[32] Kaur S. Prevalence and molecular epidemiology of group A rotavirus among children and animal in North India [Ph.D. dissertation]. Izatnagar, Uttar Pradesh, India: Indian Veterinary Research Institute; 2011.

[33] Rai RB, Hansha A, Rai S, Singh B, Kumar H, Singh AK, Damodaran T, Dhama K. Prevalence of rota and coronavirus infections in calves of Barabanki and Raebareli districts of Uttar Pradesh. Indian J Vet Pathol. 2011; 35(1):73-74.

[34] Falcone E, Tarantino M, Di Trani L, Cordioli P, Lavazza A, Tollis M. Determination of bovine rotavirus G and P serotypes in italy by PCR. J Clin Microbiol. 1999; 37(12):3879-3882.

[35] Al-Robaiee IA, Al-Farwachi MI. Prevalence of rotaviral infection in diarrheic neonatal calves in Mosul city, Iraq. Vet World. 2013; 6:538-540.

[36] Conneely M, Berry DP, Sayers R, et al. Factors associated with the concentration of immunoglobulin G in the colostrum of dairy cows. Animal. 2013; 7(11):1824-1832.

[37] Morrill KM, Conrad E, Lago A, Campbell J, Quigley J, Tyler H. Nationwide evaluation of quality and composition of colostrum on dairy farms in the United States. J Dairy Sci. 2012; 95(7):3997-4005.

[38] Madadgar O, Nazaktabar A, Keivanfar H, Zahraei Salehi T, Lotfollah Zadeh S. Genotyping and determining the distribution of prevalent $G$ and $P$ types of group A bovine rotaviruses between 2010 and 2012 in Iran. Vet Microbiol. 2015; 179(3-4):190-196. 
[39] Dhama K, Chauhan RS, Mahendran M, Malik SV. Rotavirus diarrhea in bovines and other domestic animals. Vet Res Commun. 2009; 33(1):1-23.

[40] Sravani GV, Kauer DG, Chandra M, Dwivedi PN. P and G genotyping of bovine rotavirus and its prevalence in neonatal calves. Vet Arhiv. 2014; 84(16):475-484.

[41] Al-Robaiee IA, Al-Farwachi MI. Prevalence of rotaviral infection in diarrheic neonatal calves in Mosul city, Iraq. Vet World. 2017; 6(2):538-540.

[42] Gentsch JR, Laird AR, Bielfelt B, et al. Serotype diversity and reassortment between human and animal rotavirus strains: implications for rotavirus vaccine programs. J Infect Dis. 2005; 192 Suppl 1:S146-S159.

[43] Pitzer VE, Patel MM, Lopman BA, Viboud C, Parashar UD, Grenfell BT. Modeling rotavirus strain dynamics in developed countries to understand the potential impact of vaccination on genotype distributions. Proc Natl Acad Sci U S A. 2011; 108(48):19353-19358.

[44] Pérez-Ortín R, Santiso-Bellón C, Vila-Vicent S, Carmona-Vicente N, Rodríguez-Díaz J, Buesa J. Rotavirus symptomatic infection among unvaccinated and vaccinated children in Valencia, Spain. BMC Infect Dis. 2019; 19(1):998.

[45] Soares-Weiser K, Maclehose H, Bergman H, et al. Vaccines for preventing rotavirus diarrhoea: vaccines in use. Cochrane Database Syst Rev. 2012; 11:CD008521.

[46] Velázquez FR. Protective effects of natural rotavirus infection. Pediatr Infect Dis J. 2009; 28(3 Suppl):S54-S56.

[47] Bain R, Cronk R, Wright J, Yang H, Slaymaker T, Bartram J. Fecal contamination of drinking-water in low- and middle-income countries: a systematic review and meta-analysis. PLoS Med. 2014; 11(5):e1001644.

[48] Rebato ND, de Los Reyes VCD, Sucaldito MNL, Marin GR. Is your drinking-water safe? A rotavirus outbreak linked to water refilling stations in the Philippines, 2016. Western Pac Surveill Response J. 2019; 10(1):1-5.

[49] Todd ECD. Foodborne disease and food control in the Gulf States. Food Control. 2017; 73:341-366.

[50] Adah MI, Jaji Z, Agwazim BF, el-Yuguda AD, Mani AU. Detection of human rotavirus in faeces from diarrhoeic calves in north-east Nigeria. Trop Anim Health Prod. 2002; 34(1):1-6.

[51] Pietsch C, Liebert UG. Evidence for presumable feline origin of sporadic G6P[9] rotaviruses in humans. Infect Genet Evol. 2018; 63:180-194.

[52] Crawford SE, Ramani S, Tate JE, et al. Rotavirus infection. Nat Rev Dis Primers. 2017; 3:17083.

[53] Ruggeri FM, Bonomo P, Ianiro G, et al. Rotavirus genotypes in sewage treatment plants and in children hospitalized with acute diarrhea in Italy in 2010 and 2011. Appl Environ Microbiol. 2015; 81(1):241-249.

[54] Ligon G, Bartram J. Literature Review of Associations among Attributes of Reported Drinking Water Disease Outbreaks. Int J Environ Res Public Health. 2016; 13(6):527.

[55] Martella V, Bányai K, Matthijnssens J, Buonavoglia C, Ciarlet M. Zoonotic aspects of rotaviruses. Vet Microbiol. $2010 ; 140(3-4): 246-255$.

[56] Doan YH, Nakagomi T, Aboudy Y, et al. Identification by full-genome analysis of a bovine rotavirus transmitted directly to and causing diarrhea in a human child. J Clin Microbiol. 2013; 51(1):182-189.

[57] Harb A, O'Dea M, Abraham S, Habib I. Childhood Diarrhoea in the Eastern Mediterranean Region with Special Emphasis on Non-Typhoidal Salmonella at the Human-Food Interface. Pathogens. 2019; 8(2):60.

[58] Tsugawa T, Hoshino Y. Whole genome sequence and phylogenetic analyses reveal human rotavirus G3P[3] strains Ro1845 and HCR3A are examples of direct virion transmission of canine/feline rotaviruses to humans. Virology. 2008; 380(2):344-353. 